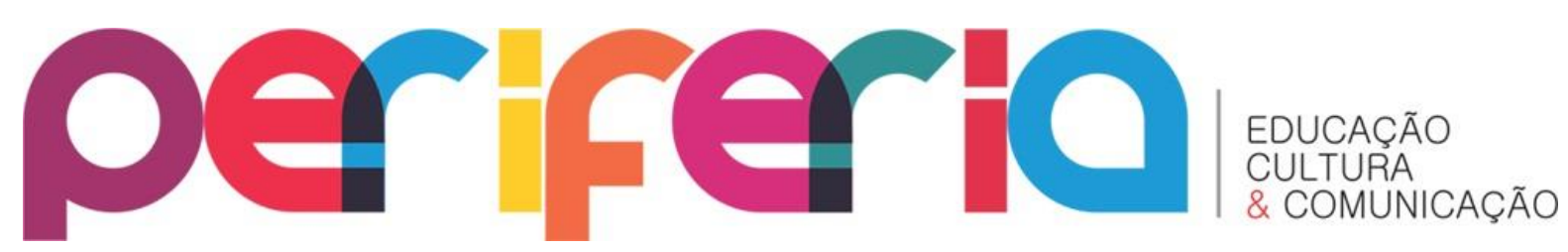

\title{
PROTAGONISMO DE SUJEITOS E GRUPOS NAS POLÍTICAS CURRICULARES
}

\author{
Rosanne Evangelista Dias ${ }^{1}$ \\ Universidade Federal do Rio de Janeiro
}

\section{RESUMO}

A produção de políticas curriculares nas últimas décadas no Brasil contou com a atuação de diferentes sujeitos e grupos, intensificada a partir do período de redemocratização do país. Em tal processo, proposições sobre as políticas curriculares foram formuladas, confrontadas e articuladas em diferentes arenas tendo em vista a consolidação de uma proposta hegemônica (LACLAU) para o país. A despeito da presença dessa atuação de sujeitos e grupos, notamos a existência de poucas análises que dêem conta dessa atuação. Defendemos, portanto, o desenvolvimento de análises orientadas pela abordagem do ciclo de políticas (BALL), a vertente das comunidades epistêmicas (ANTONIADES) e os processos de articulação por demandas (LACLAU) em diferentes contextos por reconhecer o protagonismo de sujeitos e grupos na produção das políticas curriculares.

Palavras-chave: Abordagens teórico-metodológicas; Protagonismo de sujeitos e grupos; articulação por demandas; ciclo de políticas; comunidades epistêmicas.

\section{PROTAGONISM OF SUBJECTS AND GROUPS IN POLICIES OF CURRICULUM}

\section{ABSTRACT}

The production of curriculum policies in recent decades in Brazil had the action of different subjects and groups, stepped from the period of democratization of the country. In this process, propositions about curriculum policies were formulated, confronted and articulated in different arenas in order to consolidate a hegemonic proposal (LACLAU) for the country. Despite the presence of this activities of groups and subjects, we note that there is little analysis to support its operations. We argue, therefore, the development of analysis-driven approach of the policy cycle (BALL), the slope of epistemic communities (ANTONIADES) and processes for articulating demands (LACLAU) in different contexts by recognizing the role of individuals and groups in the production curriculum policies.

Keywords: Theoretical and methodological approaches; Protagonism of subjects and groups; Articulation of demands; Policy cycle; Epistemic communities.

\footnotetext{
${ }^{1}$ Professora do Colégio de Aplicação da UFRJ e do Programa de Pós-Graduação em Educação da UFRJ, na Linha Currículo e Linguagem. Coordena atualmente a pesquisa "Processos de articulação e produção de sentidos nas políticas curriculares de formação de professores" que conta com o financiamento do CNPq, FAPERJ e UFRJ. Atua como pesquisadora do Grupo de Pesquisa "Políticas de currículo e cultura", coordenado pela Dra. Alice Casimiro Lopes (Proped/UERJ). E-mail: rosanne@ufri.br
} 


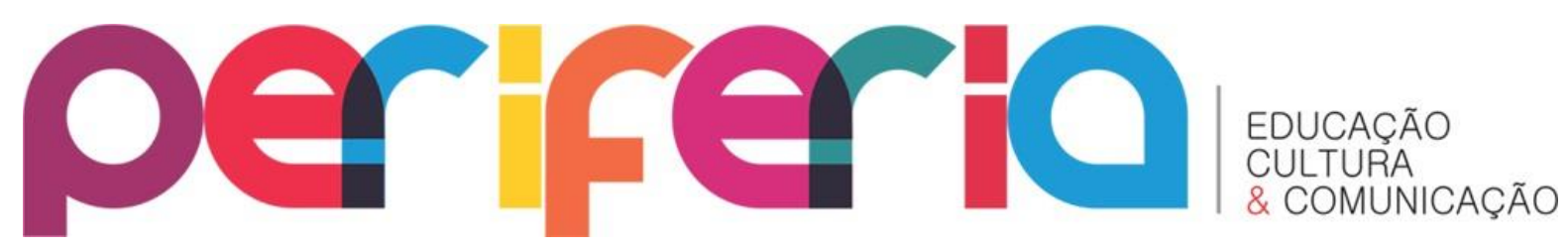

\section{INTRODUÇÃO}

A produção de políticas curriculares deve ser entendida como um processo que envolve a participação ativa de diferentes sujeitos e grupos em diversos tempos e espaços. Portanto, os textos e discursos que são objeto de análises em investigações no campo da educação não podem deixar de refletir sobre as vozes que expressam as ideias difundidas nos documentos curriculares. $O$ reconhecimento da ativa participação de sujeitos e grupos sociais nas proposições das políticas curriculares, especialmente nos anos de 1990, não pode ser ignorado. Considero intensa a produção de documentos curriculares resultado de um período conhecido pela redemocratização do país, que marcou a participação de sujeitos e grupos impulsionados pela perspectiva de formulação de propostas para diversos setores da educação como em outros campos das políticas públicas. Vários setores da sociedade civil atuaram na produção, difusão e discussão de proposições, em processos de articulação política em torno das ideias defendidas para a educação. Com a aprovação da Lei № 9.394/96 - Lei de Diretrizes e Bases da Educação Nacional (LDB/96), importante texto de definição de políticas para a educação, essa participação ganhou novo sentido diante das configurações que estavam sendo definidas nos marcos do processo democrático.

Por todos esses anos, uma série de sujeitos e grupos sociais participou nas arenas de luta em defesa dos projetos que representavam, influenciando em maior ou menor grau, a definição dessas políticas. Essa atuação se fez presente em diferentes contextos de produção da política como defende Ball e Bowe (1998), a partir de processos de articulação em luta por proposições que se espera ter hegemonizadas como políticas. O modelo analítico da teoria do discurso de Ernesto Laclau (1993, 2005, 2006) sobre os processos de articulação de demandas contribui nas investigações de políticas curriculares por considerar não apenas os sujeitos que nelas atuam, como também a dinâmica de negociação de sentidos que envolvem as políticas. Defendo, portanto, a contribuição de Ball $(1994,1998)$ e Laclau $(1993,2005$, 2006) para orientar as nossas investigações em políticas públicas curriculares. Entre os 


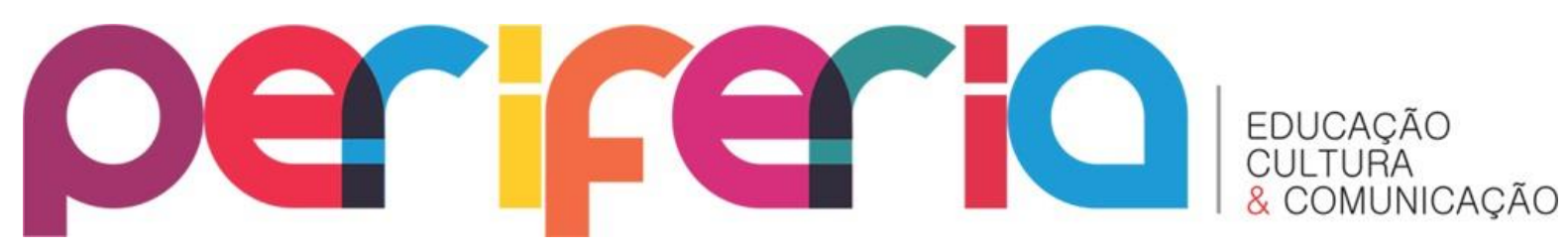

méritos das abordagens desses autores está o de focalizar as análises relacionais como macro e micro; global e local; a contingência e a provisoriedade das políticas presentes nesses processos caracterizados pela complexidade. Não pretendo com essas perspectivas defender o apagamento do papel do Estado ou da atuação de governos nas políticas públicas. Ao contrário, busco incluir as ações que são produtoras de políticas envolvendo a atuação de sujeitos e grupos sociais que produzem e fazem circular ideias, influenciando e definindo essas políticas e que muitas vezes ficam sem visibilidade nessas análises.

Tenciono neste trabalho apresentar as orientações teórico-metodológicas que conduzem minhas investigações e diálogos com outros grupos de pesquisa sobre política curricular nos últimos anos. Desenvolvo na primeira seção uma síntese do debate no campo das ciências sociais sobre a pesquisa desenvolvida na área de política pública, dialogando com a produção do campo da educação e destacando, particularmente as abordagens do ciclo de políticas e a vertente das comunidades epistêmicas como significativas contribuições para essas investigações. Na segunda seção, apresento as questões que orientam as pesquisas sobre o protagonismo de sujeitos e grupos e os processos de articulação na produção de políticas curriculares, apresentando os principais conceitos que defendo para a condução dessas análises a partir das contribuições de Ball e Laclau. Finalizo com considerações acerca das questões apontadas indicando as possibilidades presentes nas pesquisas sobre políticas curriculares que se pautam nas abordagens apresentadas que tem como referência o protagonismo de sujeitos e grupos e a política como um complexo processo de articulação.

\section{POLÍTICAS PÚBLICAS: A PRODUÇÃO EM DIFERENTES CAMPOS}

A produção da pesquisa em políticas públicas tem crescido no Brasil em diversas áreas do conhecimento. No campo da educação, a produção de teses e 


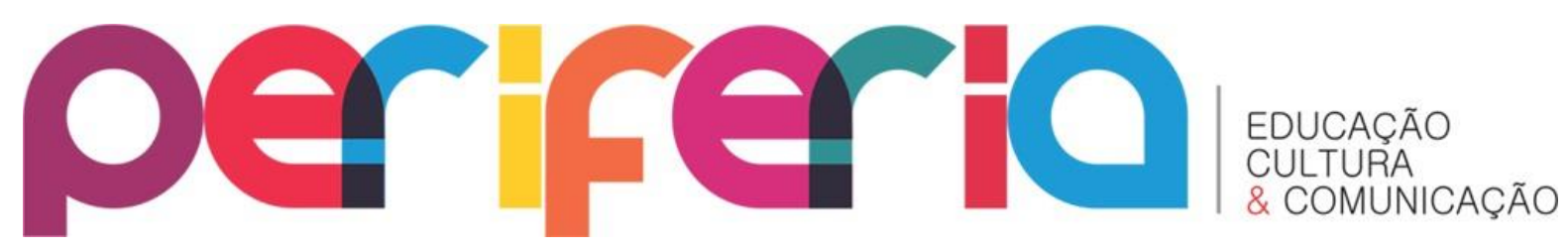

dissertações em currículo da Educação Básica² que tem como tema central a política curricular, no período de 1996 a 2002, chegou a 42,5\% (PAIVA, FRANGELLA, DIAS, 2006). Entendo que o resultado do aumento dessa produção, traz consequências de caráter teórico-metodológico (MELO \& COSTA, 1995) que devem ser enriquecidas pelo debate entre os campos das ciências sociais e da educação para a compreensão sobre os limites e as possibilidades das pesquisas sobre políticas públicas no atual contexto.

Uma das críticas desenvolvidas pelos pesquisadores de políticas públicas nas ciências sociais diz respeito à existência de microabordagens contextualizadas desvinculadas de análises dos processos macro e limitadas no tempo, falhando na busca de inter-relações entre os processos investigados (FREY, 2000). Este problema está intimamente vinculado à relação macro e micro, objeto de debate também no campo da educação. Muitas vezes, os aspectos macro e micro são expressos nas investigações sobre políticas ressaltando a dicotomia e a unilateralidade entre as instâncias (LOPES, 2005, BRANDÃO, 2002). Para Lopes, o problema não está na opção por investigações que priorizem empiricamente instâncias macro ou micro em suas análises, mas quando é inexistente a busca de relações entre essas instâncias, predominando o caráter determinista entre as mesmas. Os pesquisadores devem sentir-se desafiados a compreender como ambas as instâncias influenciam e estruturam, no mundo contemporâneo, um número crescente de situações em nível global e local.

Tem sido destacada, em trabalhos que analisam a produção de políticas no campo do currículo (LOPES, 2005, 2004b; PAIVA, FRANGELLA, DIAS, 2006), uma discussão voltada para a produção dos governos, explorando muito o institucional, em especial as ações no âmbito dos poderes executivo e legislativo. Outro aspecto presente é a influência das reformas no contexto da globalização no cenário político brasileiro e de outros países do mundo e a pouca presença de análises sobre o papel dos sujeitos e grupos sociais que estejam fora do quadro burocrático do Estado. Desse

\footnotetext{
${ }^{2}$ As teses e dissertações analisadas nesse trabalho são oriundas da pesquisa "Estado da Arte do currículo da educação básica no Brasil", financiada pelo INEP/PNUD e realizada no âmbito da ANPED, desenvolvida no ano de 2004.
} 


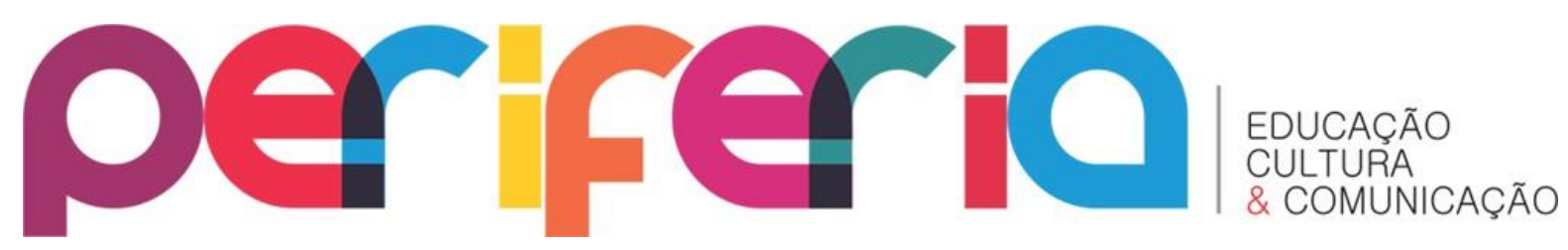

modo, lideranças que exercem influência na formulação e definição das políticas públicas acabam tendo um papel secundário nessas análises, quando elas se apresentam. Resulta assim, que na maior parte delas, silenciam os conflitos e polêmicas que cercam a política curricular, revelando o papel da política como prescritiva da prática.

Fatores exógenos, como acordos transnacionais, financiamentos promovidos por organismos internacionais, entre outros, têm um relevo significativo nas análises das políticas públicas educacionais. O destaque conferido às agências multilaterais, influenciando a produção de políticas públicas, não pode ser ignorado, mesmo por aqueles que, como eu, consideram seu papel de influência relativo. Contudo, considero a necessidade de se buscar nas análises de políticas públicas educacionais a inter-relação entre esses organismos internos e os grupos e lideranças de um país, aspecto ainda pouco presente nesses estudos.

Em uma direção distinta da que enfatiza o papel central do Estado na produção de políticas públicas, Ball incorpora em sua análise as relações entre os contextos micro e macro e as complexas influências que marcam a produção das políticas educacionais, como um processo dinâmico, introduzindo a questão da convergência de políticas que, para o autor, são influenciadas por processos que transcendem os limites da territorialidade de um Estado-Nação.

Outra perspectiva teórico-metodológica que vem sendo discutida e aprofundada na área de políticas públicas no campo das ciências sociais tem como central nas análises as políticas qual processo, vistas como práticas políticas que envolvem tensões e contradições. Um exemplo dessas abordagens que destaco é a arena, a rede e o ciclo de política que tendem a desfocar os denominados agentes decisores que concentram a atenção no processo da definição das políticas, agentes esses, muitas das vezes circunscritos à ação em cargos governamentais. O campo também tem reconhecido a existência de novos sujeitos e grupos atuando, via organizações para além dos limites territoriais e da participação de redes de especialistas (FARIA, 2003) - o caso das comunidades epistêmicas. Neste trabalho o interesse está focalizado no ciclo de políticas e nas comunidades epistêmicas. 


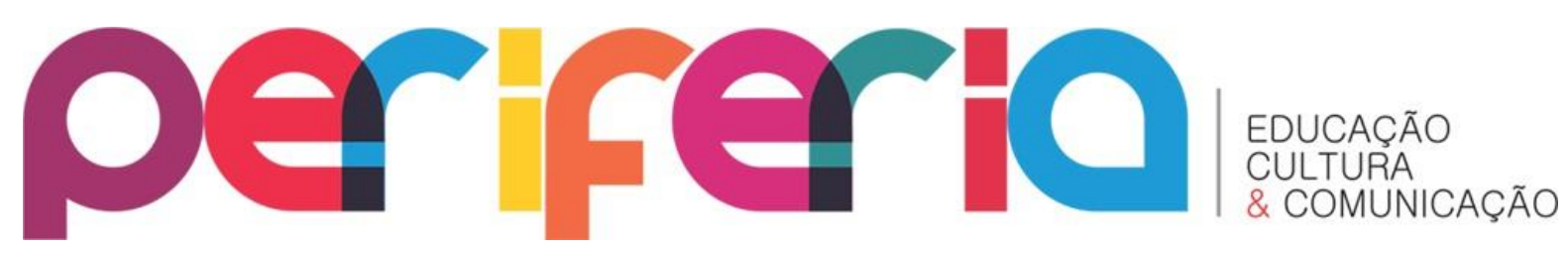

O ciclo de políticas, caracterizado pela dinâmica e complexidade temporal, assume importância como abordagem analítica por se constituir em um "modelo heurístico bastante interessante para a análise da vida de uma política pública" (FREY, 2000 , p. 226). Ao tecer um breve balanço da produção de políticas educacionais, Mainardes (2007) defende a utilização da abordagem do ciclo contínuo de políticas ${ }^{3}$ desenvolvido por Ball (1994) e Ball e Bowe (1998), como contribuição para a pesquisa no campo da educação. Destaco, ainda, que na análise do ciclo se faz presente a interação entre sujeitos e grupos sociais nacionais e internacionais na formação de agenda de políticas públicas, especialmente no contexto de globalização na qual o papel das entidades transnacionais adquire especial relevo (MELO \& COSTA, 1995). Contudo, para analisar essas interações faz-se necessário uma visão diferenciada daquela que atribui às forças externas a responsabilidade total e inexorável pelo empreendimento da política contra a qual não há espaço para "negociação".

Outra tendência apontada pela literatura das ciências sociais indica a presença, cada vez mais permanente, das ações de comunidades epistêmicas na produção e difusão de políticas. O conceito de comunidade epistêmica envolve questões como conhecimento e poder em redes de influências que atuam em arenas políticas. Essas redes, constituídas de sujeitos, na sua maior parte com atuação não governamental, congregam lideranças na área de conhecimento ou em determinada instituição/empresa/entidade. O poder da comunidade epistêmica está associado ao conhecimento ou a autoridade cognitiva, aplicado à implementação de políticas (MELO \& COSTA, 1995; ANTONIADES, 2003), mas não só a isso.

Nesses processos de formação de agenda e difusão de conhecimento, em escala global e local, faz-se muito importante não apenas o conhecimento técnicocientífico, mas, sobretudo, nos aspectos relativos à produção de consenso como base

\footnotetext{
${ }^{3}$ Nesse ciclo contínuo de políticas Ball apresenta cinco contextos que podem ser entendidos como arenas políticas nos quais o processo de produção de políticas deve ser analisado: a) contexto de influência; b) contexto de definição de textos ${ }^{3}$; c) contexto da prática; d) contexto dos resultados / efeitos; e) contexto da estratégia política. Esses dois últimos contextos resultam de uma expansão pelo autor, do ciclo contínuo de políticas, incorporando nele as preocupações com a avaliação e o impacto das políticas na alteração do quadro social. Os três primeiros contextos: influência, definição de textos e prática são para Ball os contextos primários e todos eles produtores de política curricular.
} 


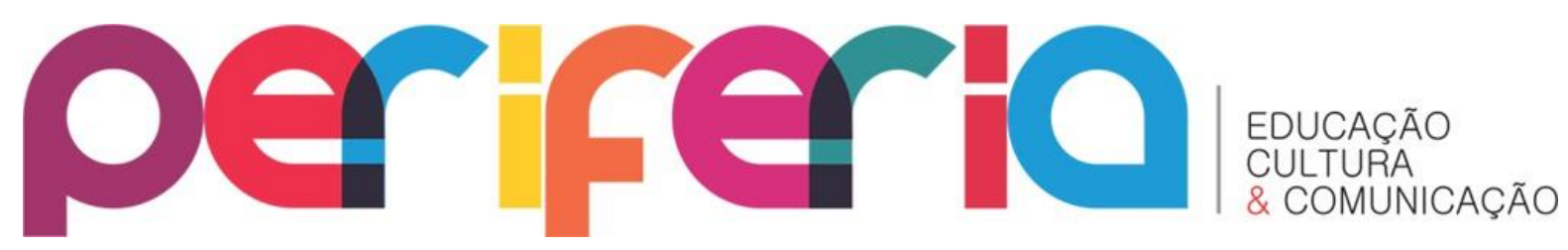

para coordenação de políticas. Embora não aprofunde a respeito da caracterização e dinâmica das comunidades epistêmicas, Ball (1998) identifica a dessas comunidades de pensamento (FARIA, 2003) influenciando de forma direta a produção de políticas educacionais por meio do fluxo de ideias disseminado em suas redes sociais e políticas. Mas, não é apenas no contexto de influência que a ação das comunidades epistêmicas se realiza. No contexto de definição de documentos curriculares, os membros de uma comunidade epistêmica são vistos participando em comissões, consultorias, conselhos, etc.

A presença de investigações utilizando a comunidade epistêmica como vertente analítica ainda é pequena no campo da educação, sendo mais notada no Brasil na discussão de políticas setoriais, na área da saúde e meio ambiente, como também no campo das relações internacionais (DIAS, 2009). Como exemplo de trabalhos que utilizam o conceito de comunidade epistêmica, cito meu próprio trabalho com López (2006) que analisa as proposições para a formação de professores e o processo de avaliação contidas no Relatório Delors (2001).

Podemos verificar o quanto a UNESCO, na sua função catalisadora de políticas, desempenha esse papel de incorporar ideias produzidas por sujeitos e comunidades com grande amplitude e também legitimando ideias e propostas que tenha a UNESCO como referência. Lopes ${ }^{4}(2006,2004 a)$ também discute o papel das comunidades epistêmicas na produção das políticas curriculares para o ensino médio, demonstrando a força com que grupos e sujeitos ligados a essa área influenciam na produção de políticas para o Brasil.

Um bom exemplo de trabalho, no campo da educação, que lança questões sobre a atuação dos sujeitos e grupos também em ações que envolvem a produção de sentidos junto aos organismos internacionais é o de Krawczyk (2001). Ela analisa a influência dos organismos internacionais nas reformas educacionais na América Latina,

\footnotetext{
${ }^{4}$ Em sua pesquisa, financiada pelo CNPq e intitulada "A produção de políticas de currículo em contextos disciplinares", Lopes utiliza-se do conceito de comunidade epistêmica (Ball) na produção de discursos sobre seleção e organização do conhecimento escolar às políticas curriculares para o ensino médio no Brasil.
} 


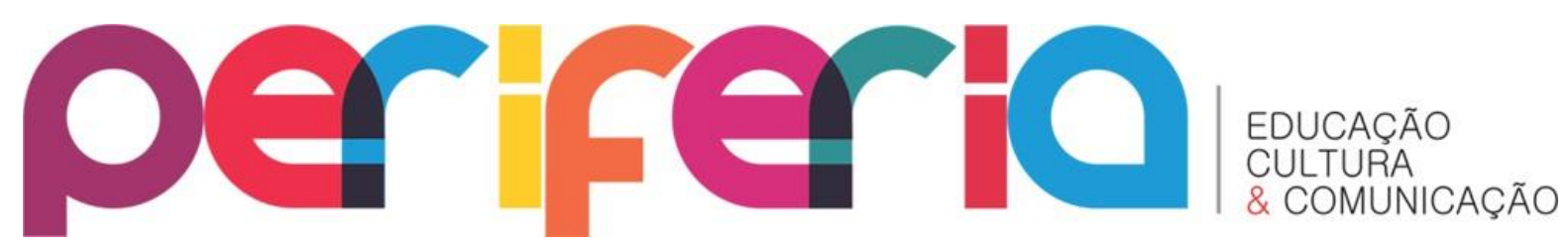

sem, contudo, avançar nos aspectos relacionais entre a participação desses sujeitos/grupos políticos e os organismos internacionais.

Cito ainda dois trabalhos importantes para as análises que incorporem o papel de sujeitos e grupos políticos na produção de políticas: os trabalhos de Hage (2003) e de Silva (2003). Ambos focalizam a ação política de grupos como associações acadêmicas, sindicatos, segmentos privados e religiosos, bem como a atuação de Fóruns cuja composição ampla permite a inclusão de vários grupos organizados da sociedade.

Embora esses dois autores se preocupem com a explicitação das tensões do processo e das disputas de projeto presentes no decurso da produção da política, ao terem como questão a luta pela hegemonia ${ }^{5}$ na construção dos projetos, desconsideram os espaços de conciliação de interesses que também se fazem presentes nesse processo complexo de produção de políticas. O processo de produção de políticas é permeado de confluências e divergências procedentes de fontes autorais distintas, o que nos permite pensar o contexto das influências nas suas múltiplas complexidades, derivadas de variadas fontes (sujeitos, grupos, organizações, etc.), espaços (em diferentes escalas) e destinação.

Considerar a atuação de sujeitos na produção de políticas nos deve fazer reconhecer as diversas identidades que participam nas ações políticas e as distintas posições assumidas pelo mesmo sujeito, no mundo contemporâneo, e as ambivalências que podem surgir derivadas dessas diferentes posições do sujeito, influenciadas também pelas inserções em grupos que defendem semelhantes posições e suas relações de poder. As diferentes formas de atuação repercutem nas distintas posições assumidas pelos sujeitos (LACLAU, 1996; MOUFFE, 1996), relacionadas aos diferentes propósitos que empreendem na luta política.

Compartilho da defesa de Laclau a respeito do pertencimento múltiplo do sujeito na vida social contemporânea, na medida em que esse pertencimento é constituído em função de diferentes lutas políticas. As posições dos sujeitos

\footnotetext{
${ }^{5} \mathrm{O}$ conceito de hegemonia empregado pelos dois autores em seus trabalhos é fundamentado na teoria do Estado de Gramsci.
} 


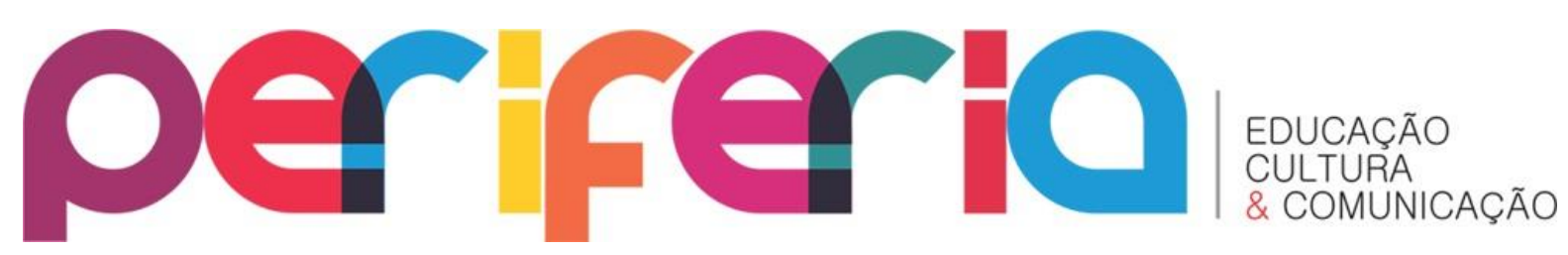

defendidas nos discursos se difundem nos variados espaços e grupos em que participam, ou nas arenas de ação (BALL, 1994), vindo a constituir, entre os vários pertencimentos, o de uma comunidade epistêmica.

Reconheço a relevância de modelos analíticos que contemplem o processo de produção da política compreendendo sua dinâmica e complexidade. Defendo o emprego das abordagens do ciclo de políticas e a vertente da comunidade epistêmica por revelarem-se extremamente úteis para as análises em políticas curriculares.

\section{PROTAGONISMO E PROCESSOS DE ARTICULAÇÃO NA PRODUÇÃO DE POLÍTICAS CURRICULARES}

$\mathrm{Na}$ investigação que defende o protagonismo de sujeitos e grupos na produção de políticas curriculares faz-se importante a análise da inter-relação entre os discursos presentes nos textos de definição política com os discursos produzidos e difundidos nos contextos da prática e de influência pelos seus autores nos diferentes textos que defendem demandas dirigidas às políticas curriculares. Concordo com Ball (1994), que as políticas são simultaneamente discursos e textos. Entendo discurso como prática social, não se dissociando a linguagem da ação e das próprias regras que a constituem. Os diferentes discursos produzidos nos variados contextos de produção curricular são recontextualizados (BERNSTEIN, 1996; 1998) por processos de hibridização (CANCLINI, 1998), com a finalidade de garantir às políticas a legitimidade, por parte de diferentes grupos, bem como articular demandas desses mesmos grupos.

A incorporação dos diferentes discursos nos documentos curriculares é resultado de um complexo processo de negociação de sentidos em torno das políticas pelos diferentes sujeitos e grupos sociais. Por não estarem fechados, nem terem seu significado fixado nem claro, os textos políticos, segundo Ball e Bowe (1998), estão submetidos a interpretações e reinterpretações de sentidos, nos diferentes contextos marcados por uma variedade de interesses. Esse processo de tradução, não é capaz de controlar por parte dos autores dos textos todos os significados, pois podem ser lidos de modo diferente nos diversos contextos em que são difundidos (BALL, 1994; BALL \& 


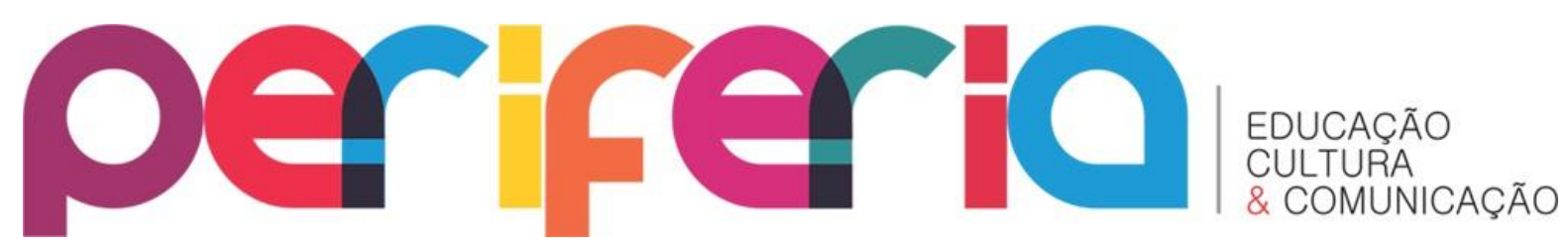

BOWE, 1998). Ressaltam ainda, esses autores, que os textos políticos possuem uma estreita relação com os contextos nos quais são produzidos e dirigidos.

Enfatizo a importância do discurso na produção dos sentidos de políticas públicas e defendo a relevância da incorporação dessa análise. Analisar os discursos como conteúdo da política, seja eles associados aos mais diversos textos, seja associados às ações e embates em curso nas arenas políticas voltadas para a produção de políticas nos variados setores, implica vê-los como expressão da prática social, constituindo-se de fundamental importância para a compreensão das influências que envolvem a política.

Esses discursos têm por finalidade influenciar o contexto da prática, nos cursos de formação de professores ou nas orientações de pesquisas que são desenvolvidas, pois é para esse contexto que são produzidos. Por outro lado, esses mesmos discursos têm, potencialmente, a capacidade de influenciar textos curriculares nos demais contextos de produção de políticas: influência, prática e definição de textos, circulando entre os diferentes contextos, com múltiplos sentidos e significados em disputa (LOPES, 2006a) estando também sujeitos a múltiplas interpretações.

Os textos, a partir dos quais são analisados os discursos sobre políticas curriculares, são todos eles, materiais caracterizados pela pluralidade (LACLAU, 1996). Essa pluralidade está presente em muitas dimensões. Há pluralidade de autores e sentidos, além da pluralidade de leituras, decorrente dos diversos sentidos e interpretações possíveis para um texto ou discurso, influenciado pelas contingências. Muitas dessas interpretações resultam em ações políticas como acordos, estabelecimento de agendas etc. (BALL, 1994). Desse modo, não podemos esperar por uma única opinião autorizada (BAUMAN, 1999) e sim por múltiplas opiniões também autorizadas que disputam o campo da significação das políticas curriculares. Isso, muitas vezes, pode vir a produzir a ambivalência nos discursos que circulam e são incorporados nos textos de definição, manifestando sua hibridização.

Devo considerar ainda as possibilidades, nesses processos de articulação, de que os sentidos sejam transferidos nos vários contextos de produção da política e que nesse processo ocorram deslizamentos interpretativos e processos de contestação 


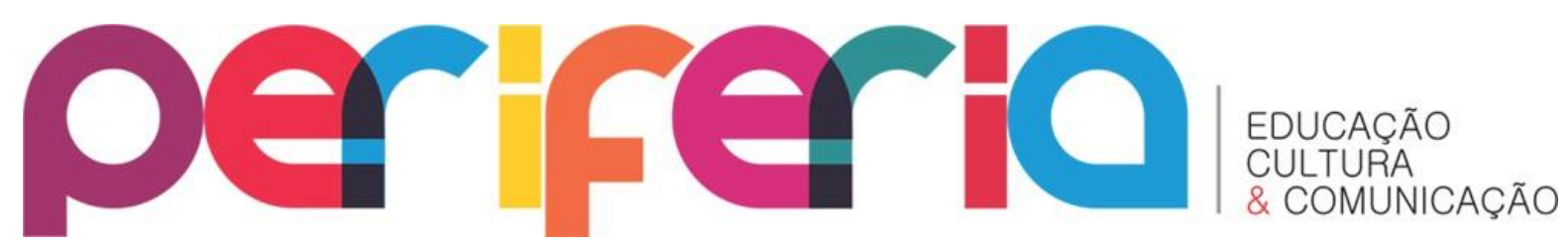

(BALL \& BOWE, 1998), capazes de dar uma nova dinâmica à produção do discurso da política. As interpenetrações de sentidos nos variados contextos não nos permite, muitas vezes, identificar a "origem" do discurso que acabou por ser legitimado e transformado em texto de definição das políticas de currículo. O processo de definição de textos políticos passa por processos de produção da política curricular baseados em articulações políticas em torno de demandas formuladas e difundidas pelos diferentes sujeitos e grupos sociais que constituem essas comunidades epistêmicas. Os discursos em torno das demandas são disputados nos diferentes contextos e visam a constituir propostas hegemônicas em meio ao processo complexo de articulação discursiva que envolve tensões e conflitos (LACLAU, 1993, 2005, 2006). Na luta pelo reconhecimento de demandas em torno dos sentidos para o currículo, há processos de incorporação pelo Estado dos discursos em defesa de demandas. As demandas emergem dos discursos e são processualmente alteradas seja pela inclusão de novas demandas, pelo deslocamento de sujeitos e grupos incorporados ou excluídos, seja pela reconfiguração delas no contexto da política (LACLAU, 2005) e na luta por políticas.

Defendo a investigação dos processos de construção de demandas e de articulação (LACLAU, 1993, 2005, 2006) em torno da política curricular a partir dos textos produzidos por sujeitos e grupos sociais nos diferentes contextos em que participam. Ao focalizar o processo de articulação de diferentes demandas podemos analisar como são estabelecidas cadeias de equivalências entre diferentes demandas, tendo como propósito uma determinada política. A lógica da equivalência não dilui ou apaga a diferença existente entre as demandas em uma mesma cadeia, mas permite a vinculação delas em torno de um propósito no qual há uma convergência, ampliando o arco de alianças.

A despeito das diferenças, as demandas estabelecem relações que aproximam umas das outras no processo de luta pela política por um projeto hegemônico, revelando toda a multiplicidade e pluralidade e seus aspectos de continuidades e descontinuidades que caracteriza esse processo. Lembro ainda que, embora possam se distinguir uma da outra no seu sentido, as demandas podem se equivaler pela oposição, ou não, em relação a uma determinada política, indicando 


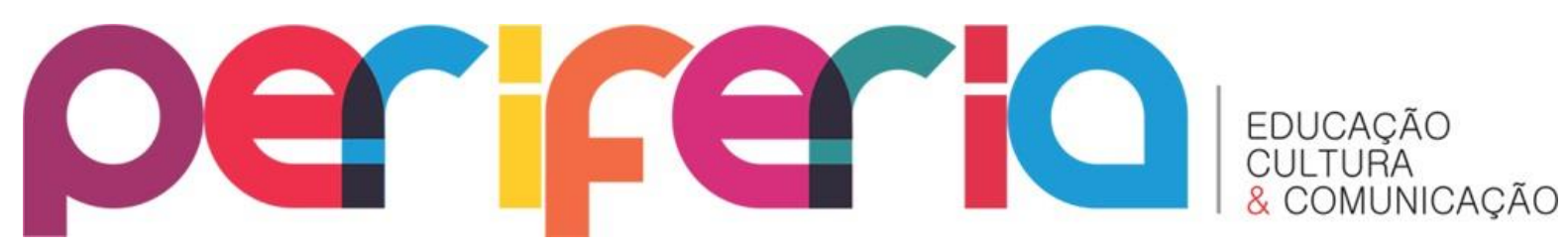

complementariedade ou tensão. Ao se aglutinarem, essas demandas acabam por constituir-se em outra com sentido geral, mais ampla, em torno de um projeto hegemônico. Esse processo deve ser visto como resultado do processo de luta pela política. Assim, há hegemonia quando uma particularidade assume certa função universal (LACLAU, 2006).

Contudo, a hegemonia é provisória e contingente, sendo o resultado da articulação de elementos em torno de certas configurações sociais, estreitamente ligada às lutas concretas de sujeitos e grupos sociais. Inserir nas análises das políticas curriculares todos os aspectos que envolvem os embates em torno das diferentes proposições que disputam a hegemonia no campo político, nos faz compreender melhor a complexidade da produção das políticas nos mais diferentes contextos.

Outra importante contribuição de Laclau para as análises das políticas curriculares é o significante vazio que resulta do processo em que uma determinada demanda deixa de estar marcada pelos seus significados particulares, de tanto que ela se estendeu em equivalências. Assim, um significante vazio é capaz de incorporar todos os sentidos possíveis, representando uma totalidade heterogênea (LACLAU, 2006), deixando de ser assumida e identificada, separadamente, pelas particularidades que as constituíram, como é, por exemplo, a demanda pela qualidade da educação. $O$ significante vazio não apaga os limites entre aquilo a que se opõe, mas para existir precisa de vê-los bem estabelecidos (LACLAU, 2005, 2006), a partir de um discurso privilegiado por ser capaz de incorporar conteúdos e sentidos diversos, mesmo que provisórios e contingentes.

Por não haver fixidez permanente nos processos políticos e na produção de políticas, existe também uma significação indefinida ou flutuante na representação das demandas que deve ser identificada nos textos curriculares. Essa dimensão flutuante está presente quando as demandas podem ser articuladas em cadeias equivalenciais alternativas em processos de pressão, na disputa de diferentes projetos hegemônicos (LACLAU, 2005). A presença de ambos os significantes, flutuantes e vazios, corresponde à complexidade da política, pois se para a constituição de políticas são necessárias as fixações de sentidos, elas não podem ser estabelecidas ad infinitum. 


\section{periferio}

\section{CONCLUSÕES}

Defendo as análises da produção de políticas curriculares em sua dinâmica de ciclo, considerando os contextos de influência, definição dos textos e prática como responsáveis pela construção dos consensos possíveis sobre as políticas (MOUFFE, 2005). Esses consensos, provisórios e contingentes, são constituídos a partir dos processos de articulação discursiva entre sujeitos e grupos sociais, que constituem as comunidades epistêmicas, a partir das demandas que vêm a influenciar a definição dos textos políticos curriculares. As opiniões autorizadas se distinguem de outras no terreno do político e, muitas vezes se opõem ou antagonizam com as posições defendidas por outros sujeitos e grupos investidos de poder. Essas posições se autoafirmam na diferença entre si, nas oposições que se constroem nas práticas cotidianas, sendo, portanto, relacionais (LACLAU, 2006; MOUFFE, 1996), sendo essas diferenças fundamentais para o processo de articulação.

Assim, um texto ambivalente carrega em si, diferentes opiniões autorizadas, ampliando a representatividade de determinado texto a partir dos grupos que venham a se sentir apoiados pelas posições expressas e ainda legitimar diferentes campos de conhecimento.

Considero que defender a inclusão dessa dinâmica de novos protagonistas na produção de políticas implica uma compreensão não verticalizada dessa produção e a necessária incorporação de análises sobre as concepções de sujeitos e grupos sociais, a partir dos textos e discursos produzidos e difundidos por eles nos contextos de produção da política curricular. Em síntese, proponho uma análise para além das personagens do cenário oficial, focalizando a investigação na produção de discursos (conteúdo das políticas) e nos sujeitos e grupos sociais/políticos que formulam, defendem e negociam ideias em torno dessas políticas nos processos políticos.

Entendo que os variados discursos que defendem, nos textos, as políticas curriculares precisam ser analisados em seus processos de tradução e recontextualização (BALL, 1998), considerados os diferentes contextos em que são 


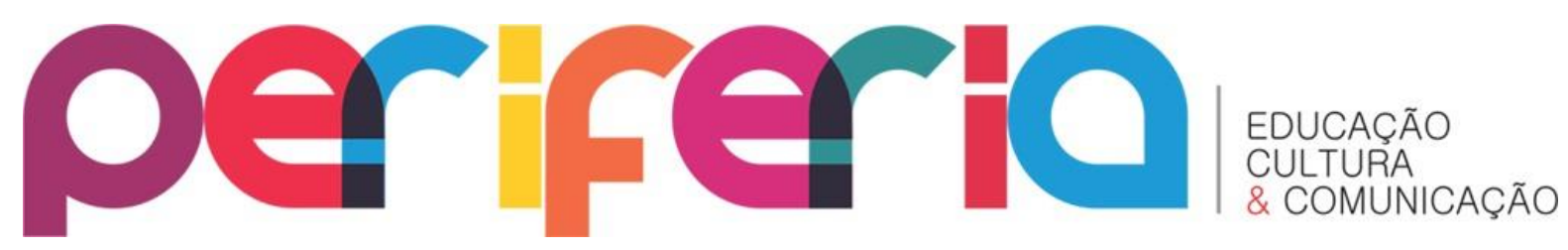

produzidos e os sujeitos e grupos sociais que neles participam. A complexidade desse processo se faz presente nos esforços, no desenvolvimento de acordos para a produção dos textos políticos, como também na interpretação dos significados atribuídos por parte dos diferentes sujeitos. Essa luta pela significação do currículo entre diferentes grupos e sujeitos está envolta em relações e tensões e tem por finalidade legitimar posições por eles defendidas em meio a diversos sentidos em disputa.

Pensar o currículo como uma política cultural pública, implica entender o currículo como uma arena de negociação de sentidos, marcado pela dinâmica de complexidade sempre contingente e provisória (LACLAU, 1996). Nesse aspecto, as demandas apresentadas importam menos pela sua origem do que pelo modo como organizam sujeitos e grupos em processos de articulação.

Outro aspecto importante na constituição do grupo relaciona-se às características heterogêneas que possibilitam as articulações entre diferentes grupos, no sentido de constituição de formação de projeto hegemônico ou mesmo do estabelecimento de limites em torno dos antagonismos entre projetos.

Defendo nas investigações sobre políticas curriculares o reconhecimento das demandas e a compreensão dos sentidos que elas expressam nas disputas políticas por significações e na constituição das comunidades epistêmicas. Reconheço que esses aspectos, presentes nos processos políticos e de constituição das políticas, permitem a construção de consensos provisórios e contingentes na definição dos textos em defesa de propostas hegemônicas marcadas pela mesma precariedade, pelo indecidível.

Tenho claro que, mesmo reconhecido o conhecimento especializado de determinado grupo social ou sujeito, outras relações de poder influem nos processos de negociação das políticas presentes nos discursos produzidos, na formulação e estabelecimento de agendas políticas, em consonância às visões de mundo dessas comunidades (ANTONIADES, 2003). Nesses processos, a política é tanto contestada quanto alterável, sempre em um estado de 'tornar-se', do 'era', e 'nunca ter sido' e 'não exatamente' (BALL, 1994), fruto da luta pela significação dos textos de definição de políticas. 


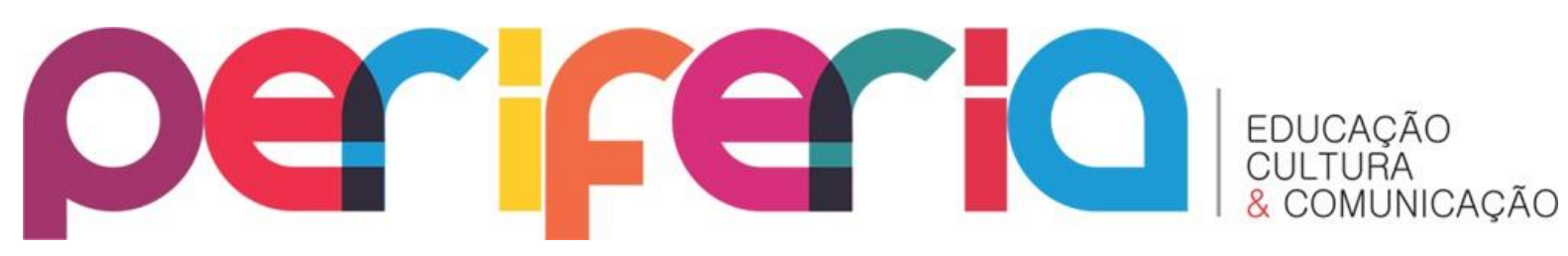

Compreendo a complexidade da realização de estudos sobre políticas públicas e o quanto o pesquisador deve estar apoiado em orientações teórico-metodológicas que o permitam realizar sua investigação visando a contribuir na produção do conhecimento e em consequentes derivações que esse trabalho pode permitir, nos mais variados campos, seja na pesquisa, na formação e seja mesmo na avaliação das políticas produzidas.

\section{REFERÊNCIAS BIBLIOGRÁFICAS}

ANTONIADES, Andreas. Epistemic communities, epistemes and the construction of (world) politics. Global society, vol. 17, n. 1, 2003, pp. 21-38.

BALL, Stephen. Education Reform: a critical and post-structural approach. Buckingham: Open University Press, 1994.

BALL, Stephen. J. Cidadania global, consumo e política educacional. In: SILVA, L.H. (Org.). A escola cidadã no contexto da globalização. Petrópolis: Vozes, 1998, pp. 121137.

BALL, Stephen. \& BOWE, Richard. El currículum nacional y su "puesta en práctica": El papel de los departamentos de materias o asignaturas. Revista de Estudios de Currículum. vol. 1, no 2, abril/1998, pp.105-131.

BAUMAN, Zygmunt. Modernidade e ambivalência. tradução Marcus Penchel. Rio de Janeiro: Jorge Zahar Ed., 1999.

BERNSTEIN, Basil. A estruturação do discurso pedagógico. Petrópolis: Vozes, 1996. BERNSTEIN, Basil. Pedagogía, Control Simbólico e Identidad. Madri: Morata, 1998.

BRANDÃO, Zaia. Para além das ortodoxias: a dialética micro/macro na sociologia da educação. In: BRANDÃO, Zaia. (CDRom) Anais da 25a Reunião Anual da Associação Nacional de Pós-Graduação e Pesquisa em Educação. Caxambu, out./2002, 9 pp.

CANCLINI, Nestor Garcia. Culturas Híbridas: estratégias para entrar e sair da modernidade. 2 2a edição. São Paulo: Editora da Universidade de São Paulo, 1998.

DELORS, Jacques (org.) Educação: um tesouro a descobrir. Relatório para a Unesco da Comissão Internacional sobre a Educação para o século XXI. São Paulo: Cortez; Brasília, DF: MEC, UNESCO, 2001.

DIAS, Rosanne Evangelista. Ciclo de políticas curriculares na formação de professores no Brasil (1996-2006). Tese de doutorado. Faculdade de Educação - UERJ, 2009, 248p.

DIAS, Rosanne E. \& LÓPEZ, Silvia B. Conhecimento, poder e interesse na produção de políticas curriculares. Currículo sem fronteiras. v.6, no 2, pp. 53-66, Jul./Dez.2006 Disponível em: <www.curriculosemfronteiras.org> Acessado em: 23 de outubro 2006, às $10 h$.

FARIA, Carlos Aurélio Pimenta de. Ideias, conhecimento e políticas públicas: um inventário sucinto das principais vertentes analíticas recentes. Revista Brasileira de Ciências Sociais. vol 18, no 51, fevereiro/ 2003, pp. 21-29. 


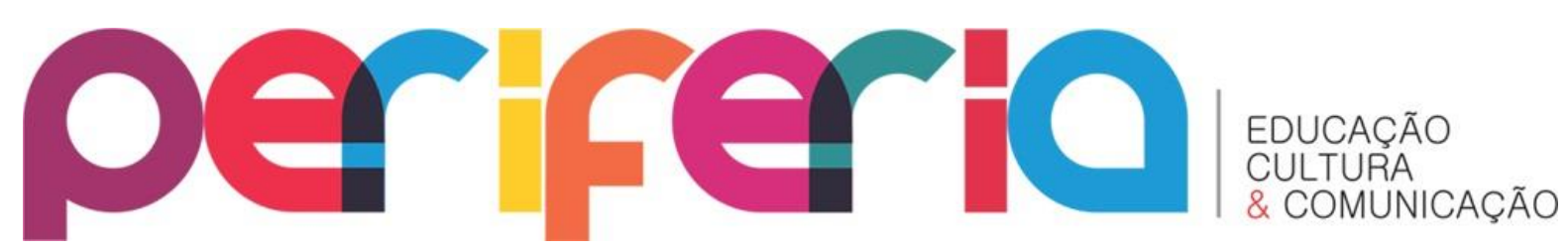

FREY, Klaus. Políticas públicas: um debate conceitual e reflexões referentes à prática da análise de políticas públicas no Brasil. Planejamento e Políticas Públicas. no 21, junho de 2000, pp.211-259.

HAGE, Salomão A. M. Guerra cultural pela escola o Brasil: a disputa pela direção do Plano Nacional de Educação (1988-1999) (CDRom) Anais da 26ㅁ Reunião Anual da Associação Nacional de Pós-Graduação e Pesquisa em Educação. Poços de Caldas, out./2003, $16 \mathrm{p}$.

KRAWCZYK, Nora. A sustentabilidade da reforma educacional em questão: a posição dos Organismos Internacionais. (CDRom) Anais da 24ㅁ Reunião Anual da Associação Nacional de Pós-Graduação e Pesquisa em Educação. Caxambu, out./2001, 33 p.

LACLAU, Ernesto. Poder y representación IN: Politics, Theory and Contemporary Culture, editado por Mark Poster, Nueva York: Columbia University Press, 1993. Tradujo Leandro Wolfson

LACLAU, Ernesto. Emancipación y diferencia. Buenos Aires: Difel, 1996.

LACLAU, Ernesto. La razón populista. Buenos Aires: FCE, 2005.

LACLAU, E. Inclusão, exclusão e a construção de identidades. IN: BURITY, Joanildo \& AMARAL, Aécio. Inclusão social, identidade e diferença: perspectivas pósestruturalistas de análise social. São Paulo: Annablume, 2006. pp.21-37.

LOPES, Alice Casimiro. Políticas curriculares: continuidade ou mudança de rumos? Revista Brasileira de Educação. Rio de Janeiro/Campinas: Anped/Autores Associados. vol. 9 , no 26, Maio/Agosto, 2004a, pp. 109-118.

LOPES, Alice Casimiro. Políticas de currículo: mediação por grupos disciplinares de ensino de ciências e matemática In: LOPES, Alice C. \& MACEDO, Elizabeth. (org.) Currículo de ciências em debate. Campinas: Papirus, 2004b, pp.45-75

LOPES, Alice Casimiro. Relações macro/micro na pesquisa em educação: o caso do campo do currículo. VII Encontro de Pesquisa em Educação da Região Sudeste. Belo Horizonte: UFMG/PUC-MG, 2005, 15p.

LOPES, Alice Casimiro. Discursos nas políticas de currículo. Currículo sem fronteiras. v.6, no 2, pp. 33-52, Jul/Dez.2006 Disponível em: <www.curriculosemfronteiras.org> Acessado em: 23 de outubro 2006, às 9h10min.

MAINARDES, Jefferson. Reinterpretando os Ciclos de Aprendizagem. São Paulo: Cortez, 2007.

MELO, Marcus A. B. C. de \& COSTA, Nilson do R. A difusão das reformas neoliberais: análise estratégica, atores e agendas internacionais. In: REIS, Elisa. ALMEIDA, Maria Hermínia e FRY, Peter (orgs.) Pluralismo, espaço social e pesquisa. ANPOCS e Editora HUCITEC: São Paulo, 1995, pp.153-175.

MOUFFE, Chantal. O regresso do político. Trajectos, 32. Tradução: Ana Cecília Simões. Lisboa: Gradiva, 1996.

MOUFFE, Chantal. Por um modelo agonístico de democracia. Revista Sociologia Política. Curitiba, 25, p. 11-23, nov. 2005.

PAIVA, Edil V.; FRANGELLA, Rita de C. P. e DIAS, Rosanne E. Políticas curriculares no foco das investigações. In: LOPES, Alice C. \& MACEDO, Elizabeth (org.). Políticas de currículo em múltiplos contextos. São Paulo: Cortez, 2006 - (Série cultura, memória e currículo; v.7). pp.241-269. 


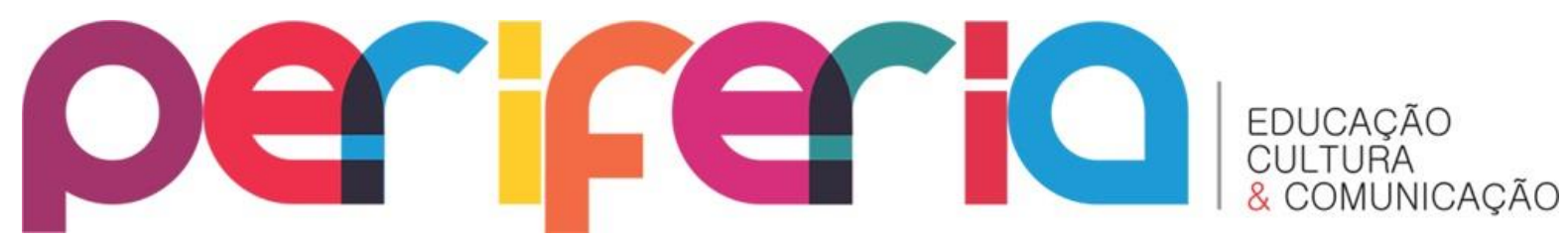

SILVA, Andréia F. da. A formação de professores para a educação básica no Brasil: projetos em disputa (1987-2001) (CDRom) Anais 26ㅁ Reunião Anual da Associação Nacional de Pós-Graduação e Pesquisa em Educação. Poços de Caldas, outubro/2003, $17 \mathrm{p}$. 